Published in the QIRT Journal, Volume 1, Issue 1

\title{
The statistical approach to the sensitivity analysis of the ThermaCAM PM595 measurement model
}

\section{Waldemar Minkina, Sebastian Dudzik}

Institute of Electronics and Control Systems, Technical University of Częstochowa, Al. Armii Krajowej 17, 42-200 Częstochowa, Tel.: (048) 3432508 56, fax.: (048) 34 3250821

Oral presentation

e-mail: minkina@el.pcz.czest.pl, sebdud@el.pcz.czest.pl

\section{KEYWORDS}

Infrared camera, measurement model, uncertainty, random variable, correlation, frequency distribution, probability density,

\section{Introduction}

In the paper, the results of the simulation sensitivity analysis of the ThermaCAM PM595 measurement model were presented. In the simulations it was assumed, that the input quantities of the model are represented by random variables. The influence of the input random variables distribution parameters on the parameters of the output random variable distribution is analyzed. The researches concern the following frequency distributions: log-normal and uniform. The simulations were carried out in the MATLAB 6.5 computational environment. The Matlab buildin routines were used. The frequency distributions of the determined parameters were generated. Additionally, the influence of the correlations between input variables on the output variable frequency distribution parameters was considered. The results of the analysis were presented as graphs and tables.

\section{The scope of the analysis}

The following model of the measurement by means of infrared camera was assumed [1,2]:

$$
u=\varepsilon_{o b} \cdot \tau_{a t m} \cdot u_{o b}+\tau_{a t m} \cdot\left(1-\varepsilon_{o b}\right) \cdot u_{a m b}+\left(1-\tau_{a t m}\right) \cdot u_{a m b}
$$

where:

$$
\varepsilon_{o b} \text { - emissivity of the object; } \tau_{a t m} \text { - transmittance of the atmosphere; }
$$

$u_{a m b}-$ the value of signal equal to the radiation.

ambient radiation, $u_{o b}-$ the value of signal equal to the object

The temperature of the object, measured using ThermaCAM PM595 system can be expressed as: 


$$
T_{o b}=\frac{B}{\ln \left(\frac{R}{u_{o b}}+F\right)},
$$

$R, B, F-$ Calibration constants of the infrared

Using the formulas described in [1], the mathematical model of temperature measurement can be obtained as a function of five variables:

$$
T_{o b}=f\left(\varepsilon_{o b}, T_{a t m}, T_{a m b}, \varpi, d\right),
$$

where:

$\varepsilon_{o b}$ - object emissivity; $T_{\text {atm }}$ - atmosphere temperature; $T_{a m b}$ - ambient

temperature; $\omega$ - relative humidity;

$d$ - distance from the object.

The open form of the relationship (3) is reserved by FLIR Systems $®$. In the general case, the input quantities can be represented by random variables with the specified frequency distribution [3]. In the paper, the analysis of the influence of the experimental standard deviation and mean value of input variables on the experimental standard deviation and mean value of output variables was presented. In the simulations, a different correlation degree between input variables, and different frequency distributions were considered as well.

\section{The method of the analysis}

The simulation sensitivity analysis was conducted in the following steps:

- Estimation of the input variables distribution parameters, (on the basis of the specified standard uncertainties), and the uncertainty study,

- Generation of the input random variables distributions with estimated parameters,

- Simulations for the specified distributions,

- $\quad$ Analysis of the parameters of output variable distribution obtained from simulation,

- Estimation of the confidence levels of the output variable distribution parameters. 


\section{Some results of the simulations}

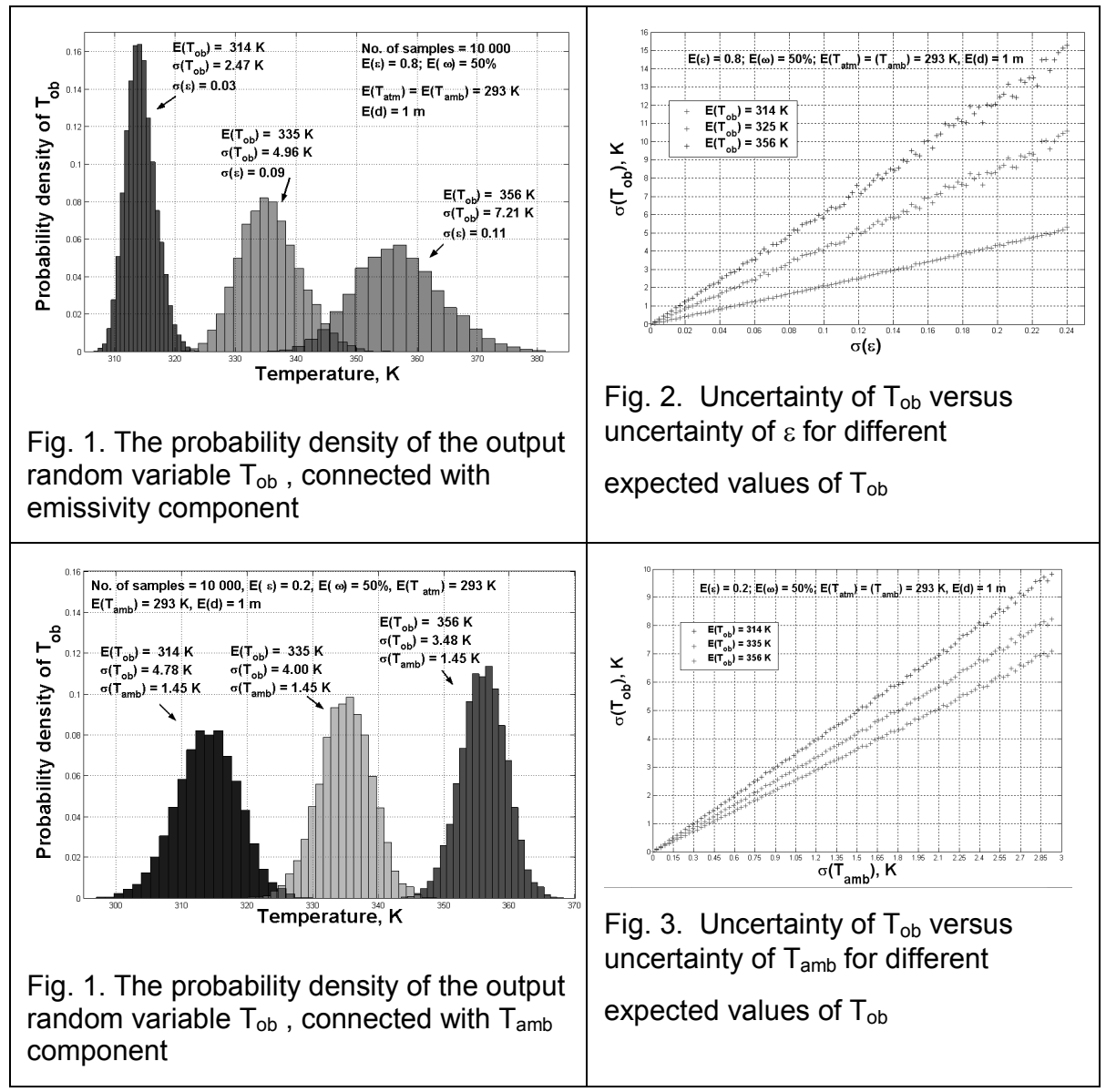

\section{Conclusions}

Wide description of the observations and conclusions will be presented in the full length paper.

\section{References}

[1] Minkina W., Bąbka R.: „Wpływ składowych błędów metody na błąd wskazania temperatury w oparciu o model pomiarowy kamery

ThermaCam PM 595”. V Konferencja Krajowa „Termografia i

Termometria w Podczerwieni, Ustroń 14 - 16 listopada 2002r. s. 339 344.

[2] Toolkit IC2 Dig 16, Developers Guide 1.00 AGEMA 550/570. FLIR Systems reserved documentation.

[3] "Guide to the Expression of Uncertainty in Measurement". International Organization for Standardization 1993. 